\title{
Distribution and Source of Atmospheric Polycyclic Aromatic Hydrocarbons and Nitropolycyclic Aromatic Hydrocarbons in Tieling City, Liaoning Province, a Typical Local City in Northeast China
}

\author{
Ning Tang*, Yuki Araki, Kenji Tamura ${ }^{1)}$, Lijun Dong ${ }^{2)}$, Xuemei Zhang ${ }^{2)}$, Qiuhua Liu ${ }^{2)}$, \\ Ruonan $\mathbf{J i}^{2}$, Takayuki Kameda, Akira Toriba and Kazuichi Hayakawa \\ Graduate School of Natural Science and Technology, and Institute of Medical, Pharmaceutical and Health Sciences, \\ Kanazawa University, Kakuma-machi, Kanazawa 920-1192, Japan \\ ${ }^{1)}$ National Institute for Environmental Studies, 16-2, Onogawa, Tsukuba 305-8506, Japan \\ ${ }^{2}$ Shenyang Center for Disease Control and Prevention, No. 37 Qishan Zhong Road Huanggu District, Shenyang 110031, China
}

*Corresponding author. Tel: +81-76-234-4458, E-mail: tou@p.kanazawa-u.ac.jp

\begin{abstract}
Airborne particulates were collected in three different size fractions ( $>7 \mu \mathrm{m} ; 2.1-7 \mu \mathrm{m} ;<2.1 \mu \mathrm{m}$ ) by using Andersen low-volume air samplers at three sites in Tieling city, Liaoning Province, a typical local city in northeast China, in every season during the period from July 2003 to May 2004. Nine polycyclic aromatic hydrocarbons (PAHs) and seven nitropolycyclic aromatic hydrocarbons (NPAHs) in the airborne particulates were determined by HPLC with fluorescence and chemiluminescence detection, respectively. The mean total concentrations of the nine PAHs and seven NPAHs were highest at The mixed residential and light industrial site, and lowest at the residential site near the suburbs. At all sites, more than $70 \%$ of the total PAHs and more than $60 \%$ of the total NPAHs were found in the finest particulate $(<2.1$ $\mu \mathrm{m})$ fraction. Both cluster analysis and several diagnostic ratios showed that the major contributors of PAHs and NPAHs in airborne particulates were coal combustion systems such as domestic stoves and coal boilers in all seasons in Tieling city.
\end{abstract}

Key words: Polycyclic aromatic hydrocarbons (PAHs), Nitropolycyclic aromatic hydrocarbons (NPAHs), Airborne particulate, Coal combustion, Tieling city

\section{INTRODUCTION}

Polycyclic aromatic hydrocarbons (PAHs) and nitropolycyclic aromatic hydrocarbons (NPAHs) are air pollutants, and many of them have carcinogenic and/ or mutagenic properties (Matsumoto et al., 1998; Toki- wa et al., 1986). The International Agency for Research on Cancer (IARC) has categorized several PAHs such as benzo[ $a]$ pyrene $(\mathrm{BaP})$ and several NPAHs such as 1,6-, 1,8-dinitrpyrenes (DNPs) and 1-nitropyrene (1-NP) in group 2A (probably carcinogenic to humans) or 2B (possibly carcinogenic to humans) (IARC, 2006). Several PAHs also exhibit estrogenic, antiestrogenic or antiandrogenic acitivities (Kizu et al., 2000). Therefore, it is necessary to clarify the distribution and contributors of PAHs and NPAHs in the atmosphere.

Atmospheric PAHs and NPAHs mainly originate from imperfect combustion and pyrolysis of organic matters, although a part of NPAHs are formed in the atmosphere via reactions of their parent PAHs (Hayakawa et al., 1995; Rogge et al., 1993; Arey et al., 1986). In urban areas, because the contribution of natural sources, such as spontaneous forest burning and volcanic emissions, of PAHs and NPAHs is limited, they are mainly emitted from automobiles, cooking, power plants, domestic heating and industrial processes. According to our previous studies, the main contributors of atmospheric PAHs and NPAHs were automobiles, especially diesel-engine vehicles in Japanese and South Korean commercial cities (Sapporo, Kanazawa, Tokyo and Seoul), while coal combustion systems such as factories and heaters in Chinese and far-eastern Russian cities (Shenyang, Fushun and Vladivostok) (Lin et al., 2005; Tang et al., 2005; Kakimoto et al., 2002; Tang et al., 2002a, b; Hayakawa et al., 2000; Kakimoto et al., 2000).

Liaoning Province is a political and economic center of northeast China and one of the main areas of heavy chemical industries in China. We previously studied characteristic features of atmospheric PAHs and NPAHs in two typical big cities, Shenyang and 


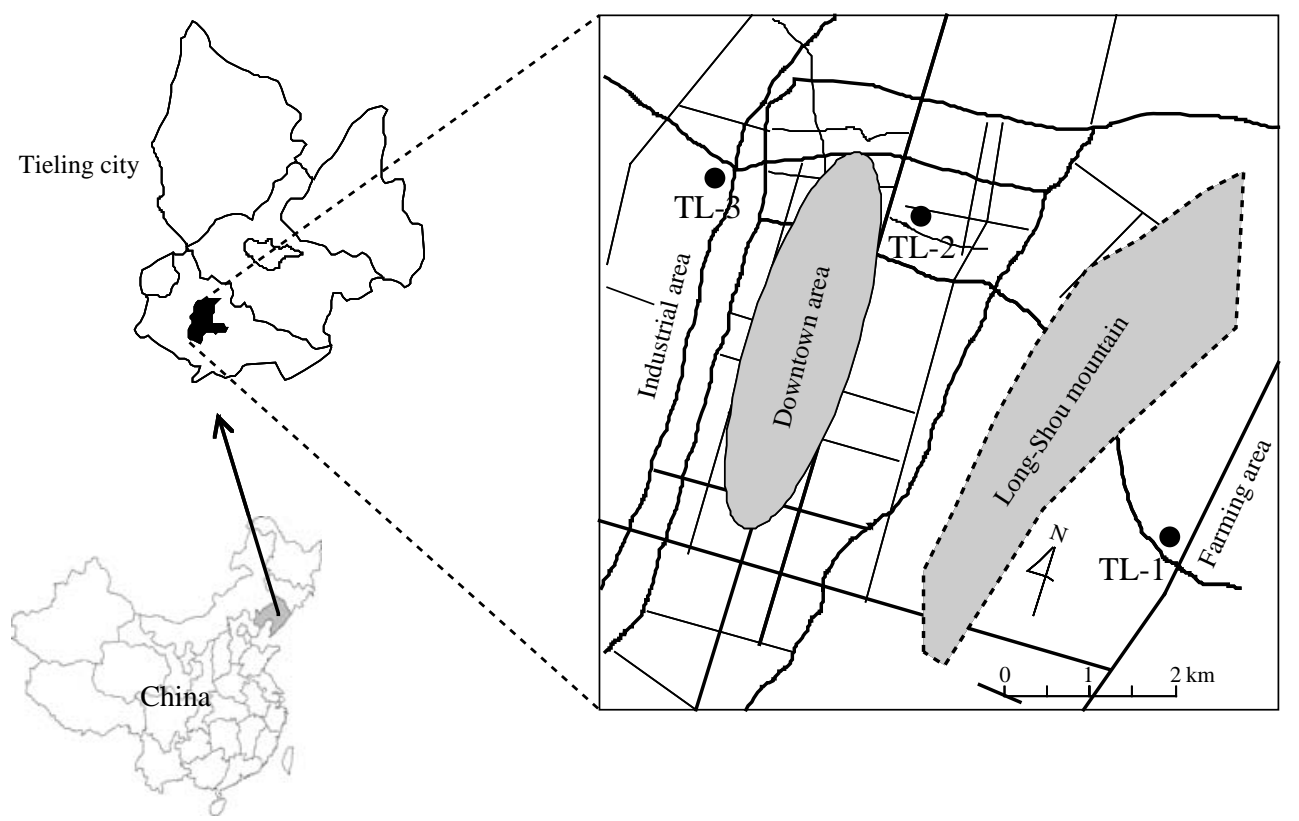

Fig. 1. Location of Tieling city with air sampling sites.

Fushun in Liaoning Province. Shenyang city is a commercial city in center of Liaoning Province. The main contributors of atmospheric PAHs and NPAHs in Shenyang city were automobiles and domestic heating in summer and winter, respectively. Fushun city is an industrial city located to the east of Shenyang city. The main contributors of atmospheric PAHs and NPAHs in Fushun city were factories in all seasons and domestic heating in winter (Lin et al., 2005; Tang et al., 2005). The information obtained from Shenyang and Fushun cities is enough to evaluate the pollution level and behaviors of atmospheric PAHs and NPAHs in commercial and industrial cities. However, Liaoning Province has 14 cities. We have not yet any information on the different types of cities of Liaoning Province. It is important to estimate the emission of PAHs and NPAHs in this area and to explain the mechanism of their long range transport to other areas (Yang et al., 2007). In this study, airborne particulates were collected in Tieling city as is a typical farming city in Liaoning Province and nine PAHs and twelve NPAHs in the airborne particulates were quantified to clarify the pollution level and behaviors of PAHs and NPAHs in Tieling city.

\section{EXPERIMENTAL}

\section{1 Sampling}

Tieling city $\left(123^{\circ} 27^{\prime}-125^{\circ} 06^{\prime} \mathrm{E} ; 41^{\circ} 59^{\prime}-43^{\circ} 29^{\prime} \mathrm{N}\right)$ is located in the north of Liaoning Province and abuts Shenyang (Fig. 1). It has a continental climate and a population of 430,000 in a total area of approximately $638 \mathrm{~km}^{2}$. Airborne particulates were collected simultaneously at three typical sites using Andersen lowvolume air samplers (AN-200, Shibata Sci. Tech., Tokyo, Japan) at a flow rate of $28.3 \mathrm{~L} \mathrm{~min}^{-1}$ : TL-1 (Lingdong Street, Yinzhou District) was in a residential area near the suburb; TL-2 (Beishi Road, Yinzhou District) was in a residential area near the downtown; TL-3 (Tiexi Street, Yinzhou District) was in a mixed residential and light industrial area. The height of the intake varied from 1 to $3 \mathrm{~m}$ above ground level. Airborne particulates were separately collected in only three fractions according to their aerodynamic size: larger than $7 \mu \mathrm{m}, 7-2.1 \mu \mathrm{m}$ and smaller than $2.1 \mu \mathrm{m}$ onto quartz fiber filters (2500QAT-UP, Pallflex Products, Putnam, CT, U. S. A.), because these fractions can consider to be $\mathrm{PM}_{10}$ (total 7-2.1 $\mu \mathrm{m}$ and smaller than $2.1 \mu \mathrm{m}$ fractions) and $\mathrm{PM}_{2.5}$ (smaller than $2.1 \mu \mathrm{m}$ fraction). Airborne particulates were sampled simultaneously in every season in Tieling city on July 1529, October 15-29, December 26, 2003-January 9, 2004 and May 10-24, 2004. The filters were dried in a desiccator in the dark, weighed and stored at $-20^{\circ} \mathrm{C}$ until use.

\subsection{Analytical Procedures and Quality Control}

EPA 610 PAHs mix, a mixture of 16 PAHs including 
fluoranthene (FR), pyrene (Pyr), benz $[a]$ anthracene $(\mathrm{BaA})$, chrysene $(\mathrm{Chr})$, benzo[ $b]$ fluoranthene $(\mathrm{BbF})$, benzo[ $k]$ fluoranthene $(\mathrm{BkF}), \mathrm{BaP}$, benzo $[g h i]$ perylene $(\mathrm{BgPe})$ and indeno[1,2,3-cd]pyrene (IDP) were purchased from Supelco Park (Bellefonte, PA, U. S. A). Two internal standards for PAHs (pyrene- $d_{10}\left(\mathrm{Pyr}-d_{10}\right)$ and benzo $[a]$ pyrene- $\left.d_{12}\left(\mathrm{BaP}-d_{12}\right)\right)$ were purchased from Wako Pure Chemicals (Osaka, Japan). 1,3-, 1,6-, 1,8-Dinitropyrenes (DNPs), 1-NP, 2-, 9-nitroanthracene (NAs), 4-nitrophenathrene (4-NPh), 3-nitrofluoranthene (3-NFR), 6-nitrochrysene (6-NC), 7-nitrobenz[a] anthracene (7-NBaA), 3-nitroperylene (3-NPer), 6nitrobenzo $[a]$ pyrene $(6-\mathrm{NBaP})$ and an internal standards for NPAHs (2-fluoro-7-nitrofluorene (FNF)) were purchased from Chiron AS (Trondheim, Norway). All other chemicals used were of analytical reagent grade.

The filters of each group were cut into small pieces and placed in a flask. Both PAHs and NPAHs were extracted ultrasonically twice with benzene/ethanol (3 $: 1, \mathrm{v} / \mathrm{v})$ and then the solution was filtered. Internal standards, Pyr- $d_{10}, \mathrm{BaP}-d_{12}$ and FNF, were added to the flask prior to the ultrasonic extraction. In the case of PAHs, the filtrate was evaporated to dryness. The residue was dissolved in $0.5 \mathrm{~mL}$ of acetonitrile, and then injected into the HPLC system for PAHs. In the case of NPAHs, the filtrate was washed with $5 \%(\mathrm{w} / \mathrm{v})$ sodium hydroxide solution, $20 \%(\mathrm{v} / \mathrm{v})$ sulfuric acid solution and water. Then the solution (filtrate) was evaporated to dryness. The residue was dissolved in 1 $\mathrm{mL}$ of $75 \%$ ethanol- $0.02 \mathrm{M}$ acetic acid-sodium acetate buffer (pH 5.5). The solution was filtered with a 0.45 $\mu \mathrm{m}$ HLC-Disk membrane filter (Kanto Chemical Co., Inc., Tokyo, Japan), and an aliquot of this solution was injected into the HPLC system for NPAHs. Other conditions were the same as in our previous reports (Tang et al., 2002a; Hayakawa et al., 1991).

The nine PAH species were determined by using HPLC with fluorescence detection. The HPLC system consisted of a reversed-phase column (Inertsil ODSP, 4.6 i.d. $\times 250 \mathrm{~mm}$, GL Sciences Inc., Tokyo, Japan) with an acetonitrile/water gradient and fluorescence detection. The flow rate was $1 \mathrm{~mL} \mathrm{~min}{ }^{-1}$. The time program of the fluorescence detector was set to detect at the optimum excitation and emission wavelengths for each PAH. Other conditions were the same as in our previous report (Tang et al., 2002a).

The twelve NPAH species were determined by using HPLC with chemiluminescence detection. The HPLC system consisted of two reversed-phase columns (Cosmosil 5C18-MS, 4.6 i.d. $\times(250+150) \mathrm{mm}$, Nacalai Tesque, Tokyo, Japan) connected in series with chemiluminescence detection. The mobile phase was 10 $\mathrm{mM}$ imidazole buffer ( $\mathrm{pH}$ 7.6)-acetonitrile $(1: 1, \mathrm{v} / \mathrm{v})$, and the chemiluminescence reagent solution was an acetonitrile solution containing $0.02 \mathrm{mM}$ bis(2,4,6-trichlorophenly)oxalate and $15 \mathrm{mM}$ hydrogen peroxide. The flow rate was $1 \mathrm{~mL} \mathrm{~min}^{-1}$ for each solution. Other conditions were the same as in our previous reports (Tang et al., 2003; Hayakawa et al., 2001).

The quartz fiber filters used for collecting particulate-bound PAHs and NPAHs were pre-heated at $600^{\circ} \mathrm{C}$ for 4 hours before using it to lower their PAHs and NPAHs blank values. Field blanks, which accompanied samples to the sampling sites, were used to determine any background contamination. No contamination was found during traveling of blank samples. Recovery and quantification of individual PAH and NPAH were revised using internal standards: $\mathrm{Pyr}-d_{10}$ for FR, Pyr, BaA and Chr; BaP- $d_{12}$ for BbF, BkF, BaP, BgPe and IDP; FNF for all NPAHs.

\section{3 Data Analysis}

In this study, the major sources of PAHs and NPAHs were identified by a cluster analysis with Ward's method and standardized squared Euclidean distance (Ward, 1963). The statistical analysis software program (Cluster97.xla, Ver.3.7) used in this study was kindly provided by Dr. Susumu Hayakari of Aomori Prefectural Institute of Public Health and Environment (Aomori, Japan). Since PAHs are formed though combustion at high temperature and are partly nitrated in the presence of nitrogen oxides, the yield of NPAHs from the corresponding PAHs increases with increasing in temperature. Therefore, the compositions of NPAHs to their mother PAHs are different in various sources (Tang et al., 2005). In this study, for the cluster analysis, we used the concentration ratios of 1-NP to Pyr, 7-NBaA to $\mathrm{BaA}$ and $6-\mathrm{NBaP}$ to $\mathrm{BaP}$ in (1) the airborne particulates collected at three sites in the three cities in this study, and (2) the CEP and DEP collected in our previous study (Tang et al., 2005).

\section{RESULTS AND DISCUSSION}

\section{1 Concentrations of PAHs and NPAHs}

The annual mean concentrations of nine PAHs and twelve NPAHs are shown in Table 1. Each figure represents the average value of all sites. The most abundant PAH was FR. Among the NPAHs, the concentration of 1,3-, or 1,8-DNP was the lowest while the concentration of 4-NPh was the highest at three sites. Total PAH concentrations were $314 \pm 397 \mathrm{pmol} \mathrm{m}^{-3}$ at TL-1, $322 \pm 334 \mathrm{pmol} \mathrm{m}^{-3}$ at TL-2 and $570 \pm 728$ pmol $\mathrm{m}^{-3}$ at TL-3, respectively. Total NPAH concentrations were $2.3 \pm 2.7 \mathrm{pmol} \mathrm{m}^{-3}$ at TL-1, $3.3 \pm 4.3$ pmol m $\mathrm{m}^{-3}$ at TL-2 and 7.2 $\pm 12.1 \mathrm{pmol} \mathrm{m}^{-3}$ at TL-3, 
Table 1. Concentrations of PAHs and NPAHs at three sites in Tieling city.

\begin{tabular}{|c|c|c|c|c|}
\hline \multicolumn{2}{|c|}{ Compound } & TL-1 & TL-2 & TL-3 \\
\hline & & $\overline{\text { Mean }} \mathrm{SD}$ & $\overline{\text { Mean }} \mathrm{SD}$ & Mean SD \\
\hline \multicolumn{2}{|c|}{ Particulate matter $\left(\mu \mathrm{g} \mathrm{m}^{-3}\right)$} & $140 \pm 66$ & $167 \pm 100$ & $161 \pm 100$ \\
\hline $\mathrm{PAH}\left(\mathrm{pmol} \mathrm{m} \mathrm{m}^{-3}\right)$ & $\begin{array}{l}\text { FR } \\
\text { Pyr } \\
\mathrm{BaA} \\
\mathrm{Chr} \\
\mathrm{BbF} \\
\mathrm{BkF} \\
\mathrm{BaP} \\
\mathrm{BgPe} \\
\text { IDP } \\
\text { Total PAH }\end{array}$ & $\begin{array}{c}60 \pm 96 \\
56 \pm 90 \\
36 \pm 53 \\
32 \pm 35 \\
31 \pm 29 \\
16 \pm 18 \\
28 \pm 34 \\
33 \pm 27 \\
21 \pm 20 \\
314 \pm 397\end{array}$ & $\begin{array}{c}56 \pm 74 \\
56 \pm 69 \\
38 \pm 46 \\
36 \pm 32 \\
34 \pm 23 \\
19 \pm 17 \\
32 \pm 32 \\
27 \pm 25 \\
23 \pm 22 \\
322 \pm 334\end{array}$ & $\begin{array}{c}132 \pm 221 \\
121 \pm 200 \\
61 \pm 83 \\
50 \pm 53 \\
50 \pm 31 \\
28 \pm 26 \\
52 \pm 59 \\
38 \pm 32 \\
37 \pm 27 \\
570 \pm 728\end{array}$ \\
\hline $\mathrm{NPAH}\left(\mathrm{fmol} \mathrm{m}^{-3}\right)$ & $\begin{array}{l}\text { 1,3-DNP } \\
\text { 1,6-DNP } \\
\text { 1,8-DNP } \\
\text { 2-NA } \\
\text { 9-NA } \\
\text { 4-NPh } \\
\text { 3-NFR } \\
\text { 1-NP } \\
6-N C \\
\text { 7-NBaA } \\
\text { 3-NPer } \\
\text { 6-NBaP } \\
\text { Total NPAH }\end{array}$ & $\begin{array}{c}4.0 \pm 1.1 \\
4.5 \pm 5.0 \\
5.7 \pm 7.5 \\
62 \pm 44 \\
428 \pm 469 \\
1390 \pm 2026 \\
56^{\mathrm{a}} \\
241 \pm 164 \\
293 \pm 286 \\
136 \pm 146 \\
21 \pm 14 \\
104 \pm 122 \\
2322 \pm 2762\end{array}$ & $\begin{array}{c}4.7 \pm 2.4 \\
4.3 \pm 4.7 \\
4.2 \pm 3.1 \\
25 \pm 16 \\
407 \pm 386 \\
3607 \pm 3938 \\
20^{\mathrm{a}} \\
462 \pm 363 \\
396 \pm 454 \\
101 \pm 79 \\
26 \pm 23 \\
108 \pm 132 \\
3339 \pm 4337\end{array}$ & $\begin{array}{c}6.3 \pm 2.8 \\
5.2 \pm 2.8 \\
3.8 \pm 2.3 \\
29 \pm 24 \\
621 \pm 694 \\
9346 \pm 12080 \\
108 \pm 150 \\
273 \pm 124 \\
1130 \pm 1996 \\
176 \pm 216 \\
44 \pm 54 \\
189 \pm 217 \\
7202 \pm 12173\end{array}$ \\
\hline
\end{tabular}

a: Detected in winter only.

respectively. Both PAHs and NPAHs concentrations were higher at TL-3 than at TL-2. However, airborne particulate concentrations were at the same level at TL-2 $\left(167 \pm 100 \mu \mathrm{g} \mathrm{m}^{-3}\right)$ and TL-3 $\left(161 \pm 100 \mu \mathrm{g} \mathrm{m}^{-3}\right)$. This is because of the higher concentrations of PAHs and NPAHs in the smaller particulate fraction at TL-3 (data not shown). At TL-1, the concentrations of airborne particulates $\left(140 \pm 66 \mu \mathrm{g} \mathrm{m}^{-3}\right)$, PAHs and NPAHs were all lowest.

The concentrations of nine PAHs and four NPAHs (1,3-, 1,6-, 1-8-DNP and 1-NP) observed in Tieling city were comparable to those found in Shenyang city, and were significantly higher than those in South Korean and Japanese cities (Tang et al., 2005). This suggests that air pollution by carcinogenic and/or mutagenic PAHs and NPAHs is heavy in farming cities as well as in industrial and commercial cities in China.

\section{2 Seasonal Variations}

In general, the seasonal variation of PAHs and NPAHs is due to changes in sources, weather condition and secondary chemical reactions. The concentrations of PAHs and NPAHs are generally higher in winter than in summer (Bamford and Baker, 2003; Park et al., 2002). As shown in Fig. 2, PAHs and NPAHs concentrations were highest in winter at all three sites. The seasonal concentrations of total nine PAHs and twelve NPAHs at TL-2 and -3 were in the order: winter $>$ autumn $>$ summer $>$ spring, while the concentrations were higher in spring than in summer at TL-1. As a possible cause for the different seasonal variations observed in TL-1, the effect of the LongShou Mountain about $150 \mathrm{~m}$ above ground level which locates between TL- 1 and TL-2, -3 were considered (Fig. 1). At TL-1, the transformation of PAHs and NPAHs from both industrial and downtown areas was blocked by Long-Shou mountain and the concentrations of PAHs and NPAHs in the atmosphere might be mainly influenced by the local emission sources. The winter to summer (W/S) concentration ratios of both PAHs and NPAHs (calculated from Fig. 2) were over 10 and the concentration ratios of NPAHs to PAHs in winter were close to the ratio of coal burning exhaust particulates. This will be discussed in Fig. 5 later. These facts suggested that large amounts of PAHs and NPAHs were emitted from coal stoves and coal boilers that widely used for residential heating in Tieling city in winter.

\section{3 Particulate Partitions}

In this study, airborne particulates were separately collected in three fractions according to their aero- 

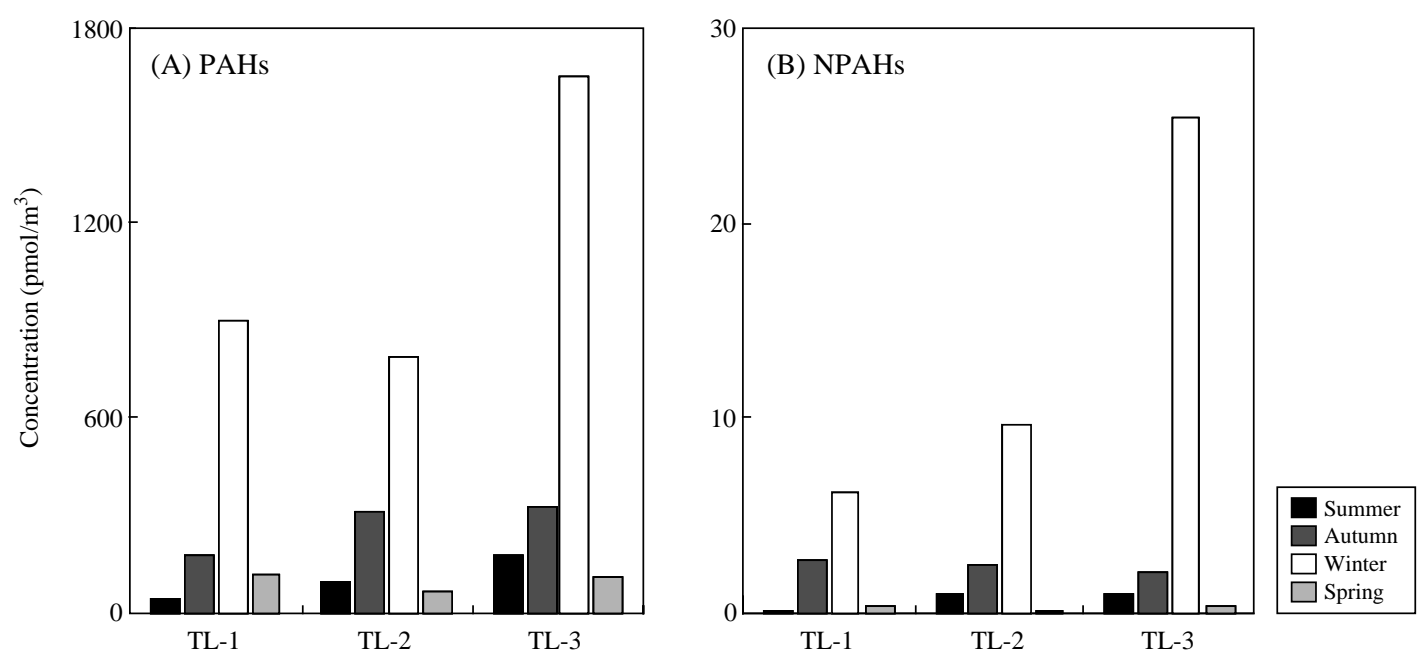

Fig. 2. Seasonal concentrations of PAHs and NPAHs at three sites in Tieling city. Each bar means the average concentration of total PAHs or NPAHs; PAHs includes FR, Pyr, BaA, Chr, BbF, BkF, BaP, BgPe and IDP; NPAHs includes 1,3-, 1,6-, 1,8-DNPs, 2-, 9-NA, 4-NPh, 3-NFR, 1-NP, 6-NC, 7-NBaA, 3-NPer and 6-NBaP.

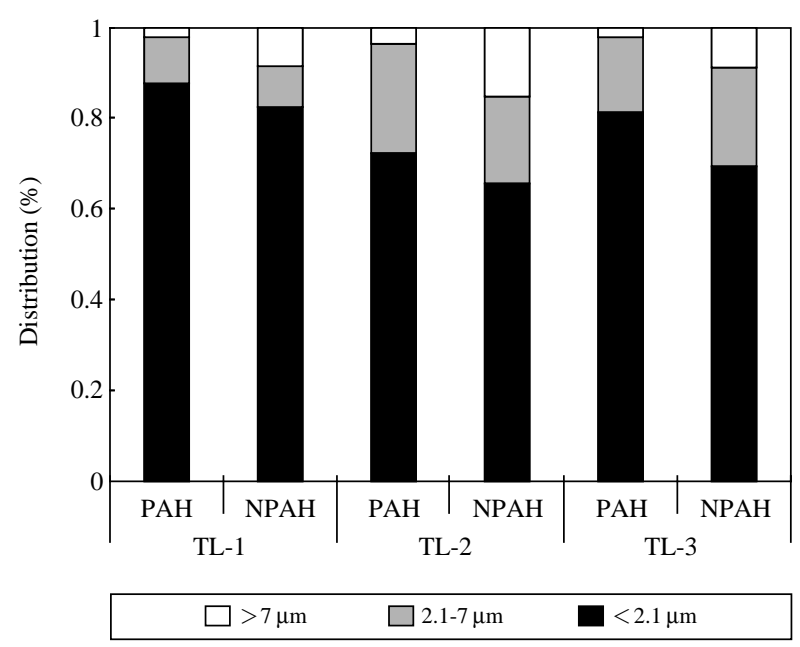

Fig. 3. Distributions of PAHs and NPAHs in three fractions at three sites in Tieling city. PAHs include FR, Pyr, BaA, Chr, $\mathrm{BbF}, \mathrm{BkF}, \mathrm{BaP}, \mathrm{BgPe}$ and IDP; NPAHs includes 1,3-, 1,6-, 1,8-DNPs, 2-, 9-NA, 4-NPh, 3-NFR, 1-NP, 6-NC, 7-NBaA, 3-NPer and 6-NBaP.

dynamic size: larger than $7 \mu \mathrm{m}, 7-2.1 \mu \mathrm{m}$ and smaller than $2.1 \mu \mathrm{m}$. As shown in Fig. 3, more than $70 \%$ and $60 \%$ of the masses of the total PAHs and total NPAHs were in the finest particulate fraction $(<2.1 \mu \mathrm{m})$ at all three sites, although the finest particulate fraction of both PAHs and NPAHs were largest at TL-2. This result suggests that the combustion apparatus for fossil fuels were the main contributors of atmospheric PAHs and NPAHs in Tieling city. This fine fraction is thought to be the most toxic because it goes deeper

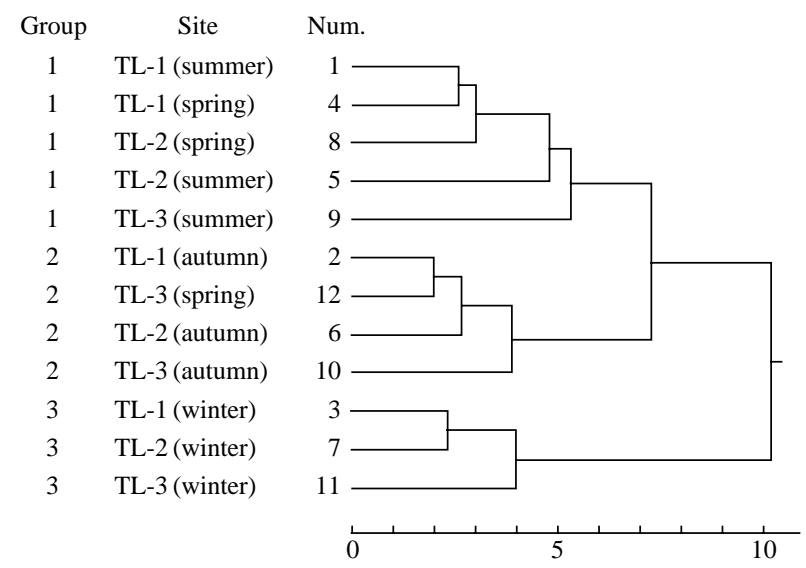

Fig. 4. Cluster analysis dendrogram of PAHs and NPAHs in airborne particulates collected at three sites in Tieling city by using Ward's method and standardized squared Euclidean distance. Prior to cluster analysis, the concentrations of individual PAHs and NPAHs were expressed as percentages of the total PAH and NPAH concentrations, respectively.

into the lungs (Lighty et al., 2000).

\section{4 Cluster Analysis}

In order to investigate the differences of composition in atmospheric PAHs and NPAHs at three sites in Tieling city, cluster analysis was used as a statistical approach. Prior to cluster analysis, the concentrations of individual PAHs and NPAHs were expressed as percentages of the total PAH and NPAH concentrations, respectively. As shown in Fig. 4, three distinct clusters were observed. Cluster 1 (Group1) includes all sum- 


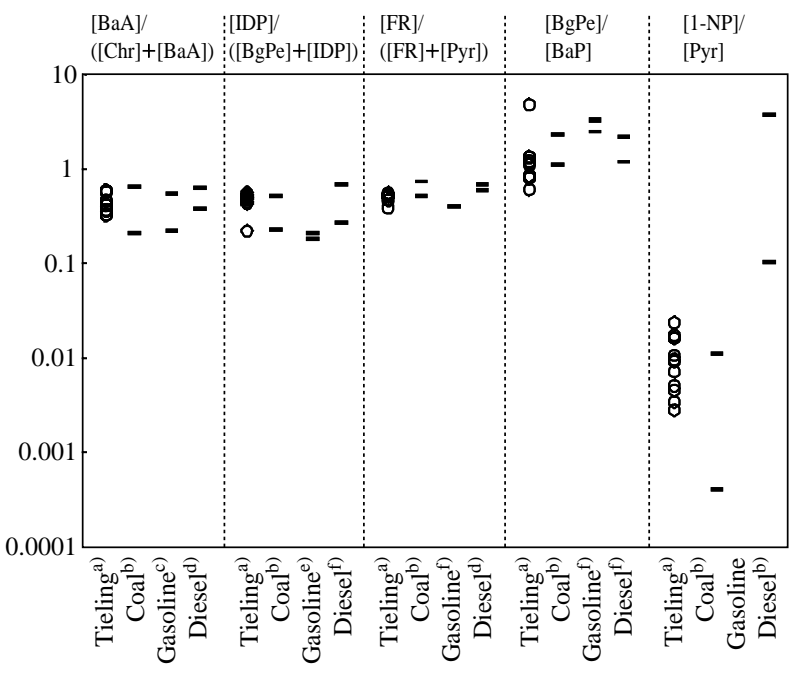

Fig. 5. Diagnostic ratios of PAHs and NPAHs in particulates

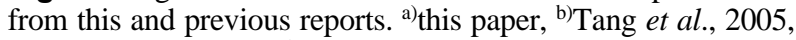

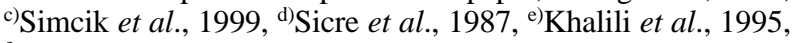
${ }^{\mathrm{f})}$ Rogge et al., 1993.

mer and spring samples collected at the three sites, except for the spring sample at TL-3. Cluster 2 (Group 2) includes all autumn samples collected at the three sites and the spring sample at TL-3. All winter samples collected at the three sites were in Cluster 3 (Group 3 ). This result indicates that the composition of PAHs and NPAHs changed seasonally at all three sites. Possible causes of the variation in PAHs and NPAHs composition are seasonal differences of (1) sources such as coal heating in winter (Matsumoto et al., 1991), (2) gas/particle partition ratios (Harner and Bidleman, 1998) and (3) atmospheric reaction conditions (Benson et al., 1985) were suggested. However, in the same season, no differences were observed in the PAH and NPAH compositions at the three sites, except in spring at TL-3. This suggests that the main seasonal source of atmospheric PAHs and NPAHs were the same at the three sites.

\subsection{Diagnostic Ratios}

Molecular diagnostic ratios can be used to identify possible emission sources of PAHs and NPAHs in the atmosphere. Among them, the concentration ratio of mono-NPAH to its parent PAH, such as [1-NP]/[Pyr], is a useful indicator for identifying the contributors of diesel car and coal combustion, since the nitration of PAH depends on combustion temperature (Tang et al., 2005). In this study, several diagnostic ratios of PAHs and NPAHs in the atmospheric particulates in Tieling city and their possible sources are shown in Fig. 5. The $[\mathrm{BaA}] /([\mathrm{BaA}]+[\mathrm{Chr}]),[\mathrm{IDP}] /([\mathrm{BgPe}]+[\mathrm{IDP}])$, $[\mathrm{FR}] /([\mathrm{FR}]+[\mathrm{Pyr}]),[\mathrm{BgPe}] /[\mathrm{BaP}]$ and $[1-\mathrm{NP}] /[\mathrm{Pyr}]$ ratios obtained in this study were in the range 0.32 $0.59,0.22-0.56,0.39-0.56,0.60-4.8$ and $0.002-0.012$, respectively. Each diagnostic ratio was close to that of coal combustion exhaust particulates (Tang et al., 2005; Simcik et al., 1999; Khalili et al., 1995; Rogge et al., 1993; Sicre et al., 1987). This suggests that coal combustion systems, such as home heating, factories and miniaturized coal boilers for daily life, might produce PAHs- and NPAHs-associating particulates in Tieling city.

\section{CONCLUSIONS}

Atmospheric PAHs and NPAHs that originated from coal combustion systems were detected in every season at three sites in Tieling city as a typical farmingcity. At all sites, the concentrations of PAHs and NPAHs were highest in winter. More than $70 \%$ of the total PAH and more than $60 \%$ of total NPAH were in the fine particulate fractions $(<2.1 \mu \mathrm{m})$ which might be most harmful to human health. Diagnostic ratios of PAHs and NPAHs suggested that the main contributor was coal combustion systems in all seasons in Tieling city.

\section{ACKNOWLEDGEMENTS}

This research was supported in part by a Grant in Aid for Scientific Research from the Ministry of Education, Culture, Sports, Science and Technology.

\section{REFERENCES}

Arey J., B. Zielinska, R. Atkinson, A.M. Winer, T. Ramdahl, and J.N. Pitts (1986) The formation of nitro-PAH from the gas-phase reactions of fluoranthene and pyrene with the $\mathrm{OH}$ radical in the presence of $\mathrm{NO}_{\mathrm{x}}$. Atmos. Environ., 20(12), 2339-2345.

Bamford H.A. and J.E. Baker (2003) Nitro-polycyclic aromatic hydrocarbon concentrations and sources in urban and suburban atmospheres of the Mid-Atlantic region. Atmos. Environ., 37(15), 2077-2091.

Benson J.M., A.L. Brooks, Y.S. Cheng, T.R. Henderson, and J.E. White (1985) Environmental transformation of 1-nitropyrene on glass surfaces. Atmos. Environ., 19(7), 1169-1174.

Harner T. and T.F. Bidleman (1998) Octanol-air partition coefficient for describing particle/gas partitioning of aromatic compounds in urban air. Environ. Sci. Technol., 32(10), 1494-1502.

Hayakawa K., K. Noji, N. Tang, A. Toriba, R. Kizu, S. Sakai, and Y. Matsumoto (2001) A high-performance liquid chromatographic system equipped with on-line reducer, clean-up and concentrator columns for deter- 
mination of trace levels of nitropolycyclic aromatic hydrocarbons in airborne particulates. Anal. Chim. Acta, 445(2), 205-212.

Hayakawa K., R. Kitamura, M. Butoh, N. Imaizumi, and M. Miyazaki (1991) Determination of diamino- and aminopyrenes by high performance liquid chromatography with chemiluminescence detection. Anal. Sci., 7(4), 573-577.

Hayakawa K., T. Murahashi, K. Akutsu, T. Kanda, N. Tang, H. Kakimoto, A. Toriba, and R. Kizu (2000) Comparison of polycyclic aromatic hydrocarbons and nitropolycyclic aromatic hydrocarbons in airborne and automobile exhaust particulates. Polycycl. Aromat. Comp., 20, 179-190.

Hayakawa K., T. Murahashi, M. Butoh, and M. Miyazaki (1995) Determination of 1,3-, 1,6-, and 1,8-dinitropyrenes and 1-nitropyrene in urban air by high-performance liquid chromatography using chemiluminescence detection. Environ. Sci. Technol., 29(4), 928-932.

International Agency for Research on Cancer (2006) IARC Monographs on the evaluation of the carcinogenic risk humans, http://monographs.iarc.fr/index.php.

Kakimoto H., M. Kitamura, Y. Matsumoto, S. Sakai, F. Kanoh, T. Murahashi, K. Akutsu, R. Kizu, and K. Hayakawa (2000) Comparison of atmospheric polycyclic aromatic hydrocarbons and nitropolycyclic aromatic hydrocarbons in Kanazawa, Sapporo and Tokyo. J. Health Sci., 46(1), 5-15.

Kakimoto H., Y. Matsumoto, S. Sakai, F. Kanoh, K. Arashidani, N. Tang, K. Akutsu, A. Nakajima, Y. Awata, A. Toriba, R. Kizu, and K. Hayakawa (2002) Comparison of atmospheric polycyclic aromatic hydrocarbons and nitropolycyclic aromatic hydrocarbons in an industrialized city (Kitakyushu) and two commercial cities (Sapporo and Tokyo). J. Health Sci., 48(4), 370-375.

Khalili N.R., P.A. Scheff, and T.M. Holsen (1995) PAH source fingerprints for coke ovens, diesel and, gasoline engines, highway tunnels, and wood combustion emissions. Atmos. Environ., 29(4), 533-542.

Kizu R., K. Ishii, J. Kobayashi, T. Hashimoto, E. Koh, M. Namiki, and K. Hayakawa (2000) Antiandrogenic effect of crude extract of C-heavy oil. Mater. Sci. Eng.: C, 12, 97-102.

Lighty J.A., J.M. Veranth, and A.F. Sarofim (2000) Combustion aerosols: factors governing their size and composition and implication to human health. J. Air \& Waste Manage. Assoc., 50(9), 1565-1618.

Lin G., G. Sun, K. Tamura, N. Tang, L. Song, and W. Zhai (2005) Analysis on concentrations of atmospheric particles and PAHs/NPAHs in Fushun, P. R. China. Chin. J. Public Health, 21, 604-606.

Matsumoto Y., S. Sakai, T. Kato, T. Nakajima, and H. Satoh (1998) Long-term trends of particulate mutagenic activity in the atmosphere of Sapporo. 1. Determination of mutagenic activity by the conventional tester strains TA98 and TA100 during an 18-year period (1974-1992). Environ. Sci. Technol., 32(18), 26652671.
Matsumoto Y., T. Nakajima, S. Sakai, I. Noguchi, and M. Akiyama (1991) Seasonal variation of the mutagenic activity of airborne particulate matter in the city of cold district. Nippon Kagaku Kaishi, 6, 837-844.

Park S.S., Y.J. Kim, and C.H. Kang (2002) Atmospheric polycyclic aromatic hydrocarbons in Seoul, Korea. Atmos. Environ., 36(17), 2917-2924.

Rogge W.F., L.M. Hildemann, M.A. Mazurek, G.R. Cass, and B.R.T. Simoneit (1993) Sources of fine organic aerosol. 2. Noncatalyst and catalyst-equipped automobiles and heavy-duty diesel trucks. Environ. Sci. Technol., 27(4), 636-651.

Sicre M.A., J.C. Marty, A. Saliot, X. Aparicio, J. Grimalt, and J. Albaiges (1987) Aliphatic and aromatic hydrocarbons in different sized aerosols over the Mediterranean Sea: Occurrence and origin. Atmos. Environ., 21(10), 2247-2259.

Simcik M.F., S.J. Eisenreich, and P.J. Lioy (1999) Source apportionment and source/sink relationships of PAHs in the coastal atmosphere of Chicago and Lake Michigan. Atmos. Environ., 33(30), 5071-5079.

Tang N., A. Toriba, R. Kizu, and K. Hayakawa (2003) Improvement of an automatic HPLC system for nitropolycyclic aromatic hydrocarbons: Removal of an interfering peak and increase in the number of analystes. Anal. Sci., 19, 249-253.

Tang N., M. Oguri, Y. Watanabe, M. Tabata, V.F. Mishukov, V. Sergienko, A. Toriba, R. Kizu, and K. Hayakawa (2002a) Comparison of atmospheric polycyclic aromatic hydrocarbons in Vladivostok, Toyama and Kanazawa. Bull. Japan Sea Res. Inst., Kanazawa Univ., 33, 77-86.

Tang N., M. Tabata, V.F. Mishukov, V. Sergienko, A. Toriba, R. Kizu, and K. Hayakawa (2002b) Comparison of atmospheric nitropolycyclic aromatic hydrocarbons in Vladivostok, Kanazawa and Toyama. J. Health Sci., 48(1), 30-36.

Tang N., T. Hattori, R. Taga, K. Igarashi, X.Y. Yang, K. Tamura, H. Kakimoto, V.F. Mishukov, A. Toriba, R. Kizu, and K. Hayakawa (2005) Polycyclic aromatic hydrocarbons and nitropolycyclic aromatic hydrocarbons in urban air particulates and their relationship to emission sources in the Pan-Japan Sea countries. Atmos. Environ., 39(32), 5817-5826.

Tokiwa H. and Y. Ohnishi, and H.S. Rosenkranz (1986) Mutagenicity and carcinogenicity of nitroarenes and their sources in the environment. Crit. Rev. Toxicol., 17(1), 23-58.

Ward J.H. (1963) Hierarchical grouping to ptimize an objective function. J. Am. Stat. Assoc., 58(301), 236244.

Yang X.Y., Y. Okada, N. Tang, S. Matsunaga, K. Tamura, J.-M. Lin, T. Kameda, A. Toriba, and K. Hayakawa (2007) Long-range transport of polycyclic aromatic hydrocarbons from China to Japan. Atmos. Envrion., 41(13), 2710-2718.

(Received 9 March 2009, accepted 17 June 2009) 